\title{
Poor quality of life and sleep in patients with adrenal insufficiency-another cause of increased mortality?
}

\author{
Antje K. Blacha ${ }^{1}$ Peter Kropp ${ }^{2} \cdot$ Amir H. Rahvar ${ }^{3} \cdot$ Jörg Flitsch $^{4} \cdot$ Iris van de Loo ${ }^{5} \cdot$ Birgit Harbeck $^{3,6}$ (i)
}

Received: 5 June 2021 / Accepted: 28 July 2021 / Published online: 13 August 2021

(C) The Author(s) 2021

\begin{abstract}
Background Patients with adrenal insufficiency (AI) are treated with glucocorticoid replacement therapy (GRT). Although current glucocorticoid regimens aim to mimic the physiological circadian rhythm of cortisol secretion, temporary phases of hypo- and hypercortisolism are common undesired effects which lead to a variety of consequences like increased cardiovascular risk and premature mortality. Additionally, poor quality of life (QoL) and impaired sleep have been reported. However, little is known about these topics regarding the effects of daily dosage, duration of therapy, and patients with different forms of AI (primary, PAI, and secondary, SAI).

Methods In this study, 40 adults with AI substituted with hydrocortisone (HC) and 20 matched healthy controls completed questionnaires evaluating depressive symptoms, subjective health status, quality of sleep and daytime sleepiness. Furthermore, demographic data, dosage of HC, duration of therapy and co-medication were evaluated. Patients were compared in different groups.

Results Patients assessed general health significantly worse than controls; likewise, daytime sleepiness was reported significantly more often. Depressive symptoms differed significantly in the two groups but did not reach clinically relevant scores. There was no difference between patients with PAI and SAI. High dosage of hydrocortisone had negative impact on mental health but not on sleep quality or daytime sleepiness.

Conclusions The present data highlight that poor QoL and impaired sleep are still severe and underrated issues in current GRT and might be additional factors for premature mortality in patients with AI. Some AI patients reach normal or nearnormal self-assessed QoL and sleep, even despite unphysiological replacement.
\end{abstract}

Keywords Adrenal insufficiency $\cdot$ Hydrocortisone $\cdot$ PAI $\cdot$ Quality of life $\cdot$ SAI $\cdot$ Sleep

\section{Introduction}

Birgit Harbeck

b.harbeck.ext@uke.de

1 I. Department of Medicine, University of Luebeck, Luebeck, Germany

2 Institute of Medical Psychology and Medical Sociology, University of Rostock, Rostock, Germany

3 III. Department of Medicine, University Medical Center Hamburg-Eppendorf, Hamburg, Germany

4 Department of Neurosurgery, University Medical Center Hamburg-Eppendorf, Hamburg, Germany

5 Diabetes-Schwerpunktpraxis Bremen, Bremen, Germany

6 Amedes Experts, Hamburg, Germany

Adrenal insufficiency (AI) is a rare endocrine disorder defined as the inability of the adrenal glands to achieve adequate hormonal production due to adrenal disease (primary AI, PAI) or due to malfunction of either the pituitary gland (secondary AI, SAI) or the hypothalamus (tertiary AI, TAI). All types of AI lead to a lack of endogenous glucocorticoids (GCs) which have to be substituted to prevent harmful symptoms that may even lead to death.

Current guidelines recommend $15-25 \mathrm{mg} / \mathrm{d}$ hydrocortisone (HC) for patients with PAI and $15-20 \mathrm{mg} / \mathrm{d} \mathrm{HC}$ for patients with SAI [1,2]. Despite splitting daily dosage into two or three portions throughout the day to mimic a physiological pattern, temporary phases of hyper- and hypocortisolism cannot be prevented [3]. Current literature reports a variety of consequences due to this unphysiological therapy: 
increased cardiovascular risk $[4,5]$, premature mortality $[6$, 7], and impaired cognitive functioning [8-10]. Restrictions in quality of life (QoL) and to a lesser degree in sleep are described as well [11-15].

Nevertheless, glucocorticoid replacement therapy (GRT) has remained almost unchanged in the past years. Co-medication with dehydroepiandrosteron (DHEA) may have positive effects on mood and fatigue [16, 17], but as yet, there are no hard criteria for use. Administration of dual-release $\mathrm{HC}$ preparations is a promising strategy to minimize problems of conventional GRT $[18,19]$.

The aim of this pilot study was to evaluate QoL and sleep in patients with AI in a complex approach. Both PAI and SAI patients were included with special focus on comparison of these patients, including additional influential factors such as daily dosage and duration of therapy.

The study protocol was approved by the Ethics Committee of the University of Luebeck, Germany (file number: 16-180), and all the participants gave written informed consent.

\section{Methods}

Forty patients (21 PAI, 19 SAI, mean age 52.7, range 20-76) on conventional GRT (2-3 daily doses, range 8-41 mg HC/d, mean: $25.8 \mathrm{mg} / \mathrm{d}$ ) completed questionnaires evaluating depressive symptoms (Beck Depression Inventory, BDI [20]), subjective health status (Short Form-36, SF-36 [21] and AddiQoL [22]), quality of sleep (Pittsburgh Sleep Quality Index, PSQI [23]), and daytime sleepiness (Epworth Sleepiness Scale, ESS [24]). The BDI is a 21 -item self-report rating inventory that measures characteristic attitudes and symptoms of depression in the previous 2 weeks. The standard cut-off scores are as follows: 0-9 points denote minimal depression, 10-18 points indicate mild depression, 19-29 points indicate moderate depression, and 30-63 points to severe depression [25]. The SF-36 tool is a 36-item, patient-reported survey of patient health. It consists of eight scaled scores, which are the weighted sums of the questions in their section. Each scale is transformed into a 0-100 scale; the lower the score, the more disability [21]. The AddiQol-30 is a self-reported disease-specific QoL questionnaire containing 30 items. In total, a maximum of 120 points can be achieved; a high sum score is connected with a high quality of life [26]. The PSQI is a self-report questionnaire assessing sleep quality over the previous 4 weeks. The measure consists of 19 different items which create 7 components that provide an overall score ranging from 0 to 21. Lower scores denote a healthier sleep quality. A PSQI total score of $>5$ is indicative of poor sleep [23]. The Epworth Sleepiness Scale (ESS) is an 8-item self-report measure of excessive daytime sleepiness. Respondents indicate on a four-point scale $(0=$ never, $3=$ high chance) the likelihood that they will "doze off or fall asleep" in eight different situations. Responses are summed to yield a total score from 0 to 24 , with higher scores indicating greater sleepiness during common daily activities. Total scores of $>7$ have been proposed to indicate excessive daytime sleepiness [24].

The results were compared to those of 20 matched (age, sex, educational background) controls. Furthermore, patients' results were compared contrasting PAI and SAI patients. Additionally, the impact of daily dosage was analyzed using median split. Other hormonal deficits were substituted adequately where necessary. Basically, both groups showed a similar distribution. Patients with antidepressant medication, regular use of anxiolytics, or other sleep-inducing drugs were excluded. Characteristics and information about participants are presented in Table 1.

Data are expressed as mean and standard deviation or as median with range where appropriate (Table 2). Results were compared using the $t$ test and the Mann-Whitney $U$ test. A $p$-value of $<0.05$ was considered significant.

\section{Results}

Although patients with AI scored significantly higher on the Beck Depression Inventory than controls (BDI median 7.0 vs. $2.0 ; p=0.001)$, clinically relevant scores were not reached. The rating of the inventory did not reveal depression in either group.

In the SF-36 AI, patients differed significantly from healthy controls and scored less for physical (SF-36 physical sum scale median 50.0 vs. 53.6; $p=0.016$ ) and mental health (SF-36 mental sum scale median 43.6 vs. $56.7 ; p=0.001$ ) than controls; their scores did not reveal substantial impaired functions. However, patients assessed general health (AddiQoL mean: 82.5 vs. $99.9 ; p=0.000$ ) significantly worse than controls.

The PSQI of patients indicated slightly compromised sleep (PSQI median 5.5 vs. 3.0; $p=0.003$ ) and more daytime sleepiness (ESS mean 9.0 vs. $6.0 ; p=0.009$ ). In particular, patients with $\mathrm{HC}$ dosage of $>24 \mathrm{mg} / \mathrm{d}$ rated mental health worse (SF-36 mental sum scale median 34.7 vs. $52.2 ; p=0.034$ ) whereas no negative impact of the daily dose was shown on quality of sleep or daytime sleepiness. Interestingly, there were no significant differences found between patients with PAI and SAI, except in general health assessed by the AddiQoL (mean 78.7 vs. 86.7; $p=0.028$ ). Analysis of co-medication showed that only four patients took DHEA. Therefore, further subgroup analysis was not feasible. Duration of therapy did not provoke any significant differences in the variables targeted. 
Table 1 Sociodemographic and disease-related data of all participants

\begin{tabular}{|c|c|c|c|c|c|}
\hline Variable & & $\begin{array}{l}\text { PAI } \\
n=21\end{array}$ & $\begin{array}{l}\text { SAI } \\
n=19\end{array}$ & $\begin{array}{l}\text { Patients } \\
\text { in total } \\
n=40\end{array}$ & $\begin{array}{l}\text { Controls } \\
n=20\end{array}$ \\
\hline \multirow[t]{6}{*}{ Age } & 20-29 years & 3 & 2 & 5 & 4 \\
\hline & $30-39$ years & 1 & 2 & 3 & 1 \\
\hline & 40-49 years & 5 & 4 & 9 & 3 \\
\hline & 50-59 years & 5 & 4 & 9 & 4 \\
\hline & $60-69$ years & 4 & 3 & 7 & 3 \\
\hline & $70+$ years & 3 & 4 & 7 & 5 \\
\hline \multirow[t]{2}{*}{ Sex } & Female & 16 & 12 & 28 & 11 \\
\hline & Male & 5 & 7 & 12 & 9 \\
\hline \multirow[t]{2}{*}{ Job } & Yes & 13 & 14 & 27 & 12 \\
\hline & No & 8 & 5 & 13 & 8 \\
\hline \multirow[t]{2}{*}{ Shift work } & Yes & 0 & 1 & 1 & 1 \\
\hline & No & 21 & 18 & 39 & 19 \\
\hline \multirow[t]{3}{*}{ Education } & Secondary school until $9^{\text {th }}$ class & 2 & 3 & 5 & 4 \\
\hline & Secondary school until $10^{\text {th }}$ class & 9 & 8 & 17 & 8 \\
\hline & University -entrance & 10 & 8 & 18 & 8 \\
\hline \multirow[t]{5}{*}{ Therapy duration } & 6-11 months & 1 & 6 & 7 & \\
\hline & $1-5$ years & 6 & 8 & 14 & \\
\hline & $6-10$ years & 0 & 2 & 2 & \\
\hline & $11-20$ years & 6 & 3 & 9 & \\
\hline & $>20$ years & 8 & 0 & 8 & \\
\hline \multirow[t]{4}{*}{ Body mass index $\left(\mathrm{kg} / \mathrm{m}^{2}\right)$} & $<18.5$ & 1 & 0 & 1 & \\
\hline & $18.5-24.9$ & 10 & 8 & 18 & \\
\hline & $25-29.9$ & 9 & 5 & 14 & \\
\hline & $\geq 30$ & 1 & 6 & 7 & \\
\hline \multirow[t]{2}{*}{ Glucocorticoid } & Hydrocortisone & 21 & 19 & 40 & \\
\hline & Plenadren & 1 & 1 & 2 & \\
\hline \multirow[t]{4}{*}{ Daily dosage (mg) } & $\leq 10$ & 0 & 1 & 1 & \\
\hline & $11-20$ & 7 & 9 & 16 & \\
\hline & $21-30$ & 9 & 6 & 15 & \\
\hline & $>30$ & 5 & 3 & 8 & \\
\hline \multirow[t]{2}{*}{ Dosage schedule } & Twice daily & 10 & 13 & 23 & \\
\hline & Three times a day & 11 & 6 & 17 & \\
\hline \multirow{6}{*}{$\begin{array}{l}\text { Additional substituted } \\
\text { endocrine deficits }\end{array}$} & Thyroxine & 11 & 12 & 23 & \\
\hline & Sex hormones & 4 & 3 & 7 & \\
\hline & Mineralocorticoids & 21 & 0 & 21 & \\
\hline & Antidiuretic hormone & 0 & 2 & 2 & \\
\hline & Growth hormone & 0 & 2 & 2 & \\
\hline & Insulin & 1 & 1 & 2 & \\
\hline
\end{tabular}

$P A I$ primary adrenal insufficiency, $S A I$ secondary adrenal insufficiency, $n$ number

\section{Discussion}

Evaluated data show that patients with AI may suffer from impaired QoL and sleep and therefore confirm and strengthen existing knowledge. However, our present data provide first evidence that patients with PAI and SAI are affected to the same degree, which indicates that the lack of cortisol is a major determinant besides other influential factors like additional hormonal imbalances. Supporting this hypothesis may also be that patients with higher dosage reached fewer points especially in the PSQI, which indicates healthier sleep. Nonetheless, these findings showed no significance, most likely caused by the small number of patients tested. Due to the short half-life of HC, cortisol levels during the night are very low in contrast to the physiological rise in the early morning. Nocturnal $\mathrm{HC}$ replacement mimicking this pattern has been analyzed before; however, data concerning the impact on sleep are still missing [27]. Cortisol is 


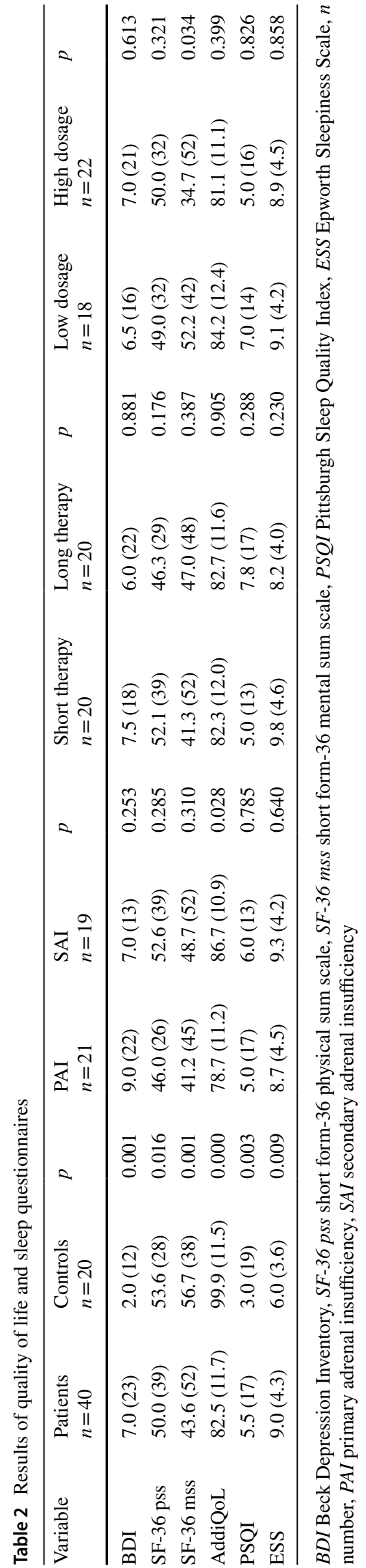

known to play a key part in initiating and maintaining different sleep stages. Part of this process is a complex interaction with other mediating substances like melatonin, adrenocorticotropic hormone, and growth hormone-releasing hormone. $\mathrm{HC}$ replacement therapy cannot fully restore this cooperation, balance nocturnal hypocortisolism, or normalize sleep architecture [13].

Sleep disturbances in healthy adolescents are associated with increased cardiovascular risk and impaired QoL [28, 29]. Consequently poor sleep quality might be an additional cardiovascular risk factor for patients with AI, facilitating already existing premature mortality. Considering that sleep also determinates QoL and compromised sleep is associated with severe impairments in QoL, which might be even mediated by mental illness [30,31], quality of sleep should be taken more into account in modern GRT.

The fact that patients with PAI showed worse results in AddiQoL than those with SAI is plausible due to the diseasespecific design of this questionnaire $[22,26]$. In addition, patients with SAI often have some small ACTH-independent residual function of adrenal cortisol secretion [32].

Our study also showed significantly higher scores in the BDI (but still in the normal range) in the examined collective of AI patients in contrast to controls. In this context, it may be interesting that patients with AI often suffer from psychiatric disorders [33, 34]. Causal research is, however, challenging due to frequent co-morbidity with other endocrine disorders [35] which are also associated with a cumulative occurrence of affective disorders [36].

The present study also demonstrated a negative correlation between high $\mathrm{HC}$ dosages and QoL, which supports previous findings [11] but contradict Buning et al. [37]. Liu et al. suggest that the function of the hypothalamus-pituitary-adrenal-axis is intensified in patients with depression, which could strengthen the idea of increased mood disorders in patients with iatrogenic hypercortisolism [38]. Nevertheless, a clear causality between $\mathrm{HC}$ dosage and reduced QoL cannot be established, as patients on higher doses may often suffer from ongoing symptoms.

Moreover, our data should be interpreted with caution due to the limited number of patients and the heterogeneity within the group of patients with adrenal insufficiency. Interestingly, there seem to be some AI patients with normal or near-normal self-assessed QoL and sleep in spite of unphysiological replacement. Therefore, further studies should especially focus on the evaluation of subgroups (e.g., patients on higher HC doses or DHEA) who presented with more serious self-rated impairment here and might benefit from replacement modifications.

To sum up, well-conducted substitution therapy should not have any side effects, but the present study emphasizes and expands findings of impaired quality of life, especially concerning general health and poor subjective quality of sleep. The cause is most probably a multidimensional 
interaction of dysfunctional hormone axes, disrupted sleep architecture and unphysiological GRT, and the reciprocal influence all of these factors should be borne in mind [39]. The present data highlight a gain in importance of psychological care and improvement of sleep to reduce cardiovascular risk and premature mortality and coincidently enhance QoL. Dual-release HC preparations need further research to verify whether they lead to improvements in this context.

Author contribution A. K. Blacha: data collection, data analysis, statistical evaluation, drafting article, P. Kropp: statistical evaluation, data analysis, A. H. Rahvar, J. Flitsch, I.van de Loo: recruitment, B. Harbeck: concept design, supervision, approval of article.

Funding Open Access funding enabled and organized by Projekt DEAL.

\section{Declarations}

Ethics approval This study was performed in line with the principles of the Declaration of Helsinki. Approval was granted by the Ethics Committee of University of Luebeck (05/21/2017, file number: 16-180).

Consent to participate Informed consent was obtained from all individual participants included in the study.

Consent for publication Informed consent was obtained from all individual participants included in the study.

Conflict of interest The authors declare no competing interests.

Open Access This article is licensed under a Creative Commons Attribution 4.0 International License, which permits use, sharing, adaptation, distribution and reproduction in any medium or format, as long as you give appropriate credit to the original author(s) and the source, provide a link to the Creative Commons licence, and indicate if changes were made. The images or other third party material in this article are included in the article's Creative Commons licence, unless indicated otherwise in a credit line to the material. If material is not included in the article's Creative Commons licence and your intended use is not permitted by statutory regulation or exceeds the permitted use, you will need to obtain permission directly from the copyright holder. To view a copy of this licence, visit http://creativecommons.org/licenses/by/4.0/.

\section{References}

1. Bornstein SR, Allolio B, Arlt W et al (2016) Diagnosis and treatment of primary adrenal insufficiency: an Endocrine Society clinical practice guideline. J Clin Endocrinol Metab 101:364-389. https://doi.org/10.1210/jc.2015-1710

2. Fleseriu M, Hashim IA, Karavitaki N et al (2016) Hormonal replacement in hypopituitarism in adults: an Endocrine Society clinical practice guideline. J Clin Endocrinol Metab 101:38883921. https://doi.org/10.1210/jc.2016-2118

3. Chan S, Debono M (2010) Replication of cortisol circadian rhythm: new advances in hydrocortisone replacement therapy. Ther Adv Endocrinol Metab 1:129-138. https://doi.org/10.1177/ 2042018810380214
4. Filipsson H, Monson JP, Koltowska-Häggström M et al (2006) The impact of glucocorticoid replacement regimens on metabolic outcome and comorbidity in hypopituitary patients. J Clin Endocrinol Metab 91:3954-3961. https://doi.org/10.1210/jc.2006-0524

5. Rahvar AH, Haas CS, Danneberg S et al (2017) Increased cardiovascular risk in patients with adrenal insufficiency: a short review. Biomed Res Int 2017:3691913. https://doi.org/10.1155/ 2017/3691913

6. Erichsen MM, Løvås K, Fougner KJ et al (2009) Normal overall mortality rate in Addison's disease, but young patients are at risk of premature death. Eur J Endocrinol 160:233-237. https://doi. org/10.1530/EJE-08-0550

7. Falhammar H, Frisén L, Norrby C et al (2014) Increased mortality in patients with congenital adrenal hyperplasia due to 21-hydroxylase deficiency. J Clin Endocrinol Metab 99:E2715E2721. https://doi.org/10.1210/jc.2014-2957

8. Blacha AK, Rahvar AH, Flitsch J et al (2021) Impaired attention in patients with adrenal insufficiency - impact of unphysiological therapy. Steroids 167:108788. https://doi.org/10.1016/j.steroids. 2020.108788

9. Henry M, Thomas KGF (2014) Episodic memory impairment in Addison's disease: results from a telephonic cognitive assessment. Metab Brain Dis 29:421-430. https://doi.org/10.1007/ s11011-014-9511-x

10. Schultebraucks K, Wingenfeld K, Heimes J et al (2015) Cognitive function in patients with primary adrenal insufficiency (Addison's disease). Psychoneuroendocrinology 55:1-7. https:// doi.org/10.1016/j.psyneuen.2015.01.025

11. Benson S, Neumann P, Unger N et al (2012) Effects of standard glucocorticoid replacement therapies on subjective well-being: a randomized, double-blind, crossover study in patients with secondary adrenal insufficiency. Eur J Endocrinol 167:679-685. https://doi.org/10.1530/EJE-12-0351

12. García-Borreguero D, Wehr TA, Larrosa O et al (2000) Glucocorticoid replacement is permissive for rapid eye movement sleep and sleep consolidation in patients with adrenal insufficiency. J Clin Endocrinol Metab 85:4201-4206. https://doi. org/10.1210/jcem.85.11.6965

13. Henry M, Ross I, Thomas KGF (2018) Reduced slow-wave sleep and altered diurnal cortisol rhythms in patients with Addison's disease. Eur J Endocrinol 179:319-330. https://doi.org/10. 1530/EJE-18-0439

14. Henry M, Wolf PSA, Ross IL et al (2015) Poor quality of life, depressed mood, and memory impairment may be mediated by sleep disruption in patients with Addison's disease. Physiol Behav 151:379-385. https://doi.org/10.1016/j.physbeh.2015.08. 011

15. Tiemensma J, Andela CD, Kaptein AA et al (2014) Psychological morbidity and impaired quality of life in patients with stable treatment for primary adrenal insufficiency: cross-sectional study and review of the literature. Eur J Endocrinol 171:171-182. https:// doi.org/10.1530/EJE-14-0023

16. Alkatib AA, Cosma M, Elamin MB et al (2009) A systematic review and meta-analysis of randomized placebo-controlled trials of DHEA treatment effects on quality of life in women with adrenal insufficiency. J Clin Endocrinol Metab 94:3676-3681. https:// doi.org/10.1210/jc.2009-0672

17. Hunt PJ, Gurnell EM, Huppert FA et al (2000) Improvement in mood and fatigue after dehydroepiandrosterone replacement in Addison's disease in a randomized, double blind trial. J Clin Endocrinol Metab 85:4650-4656. https://doi.org/10.1210/jc.85. 12.4650

18. Johannsson G, Nilsson AG, Bergthorsdottir P et al (2012) Improved cortisol exposure-time profile and outcome in patients with adrenal insufficiency : a prospective randomized trial of a 
novel hydrocortisone dual-release formulation. J Clin Endocrinol Metab 97:473-481. https://doi.org/10.1210/jc.2011-1926

19. Krekeler C, Kropp P, Blacha AK et al (2021) Dual-release hydrocortisone and its benefits on cognitive function and quality of sleep. Endocrine 72:223-233. https://doi.org/10.1007/ s12020-020-02552-6

20. Beck AT, Ward CH, Mendelson M et al (1961) An inventory for measuring depression. Arch Gen Psychiatry 4:561-571. https:// doi.org/10.1001/archpsyc.1961.01710120031004

21. Ware JE Jr (2000) SF-36 health survey update. Spine 25:3130-3139

22. Løvås K, Curran S, Oksnes M et al (2010) Development of a disease-specific quality of life questionnaire in Addison's disease. J Clin Endocrinol Metab 95:545-551. https://doi.org/10.1210/jc. 2009-1711

23. Buysee DJ, Reynolds CF 3rd, Monk TH et al (1989) The pittsburgh sleep quality index: a new instrument for psychiatric practice and research. Psychiatry Res 28:193-213. https://doi.org/10. 1016/0165-1781(89)90047-4

24. Johns MW (1991) A new method for measuring daytime sleepiness: the Epworth sleepiness scale. Sleep 14:540-545. https://doi. org/10.1093/sleep/14.6.540

25. Beck AT, Steer RA, Garbin MGJ (1988) Psychometric properties of the Beck Depression Inventory. Twenty- five years of evaluation. Clin Psychol Rev 8:77-100. https://doi.org/10.1016/02727358(88)90050-5

26. Oksnes M, Bensing S, Hulting AL et al (2012) Quality of life in European patients with Addison's disease: validity of the disease specific questionnaire AddiQoL. J Clin Endocrinol Metab 97:568-576. https://doi.org/10.1210/jc.2011-1901

27. Harbeck B, Kropp P, Mönig H (2009) Effects of short-term nocturnal cortisol replacement on cognitive function and quality of life in patients with primary or secondary adrenal insufficiency: a pilot study. Appl Psychophysiol Biofeedback 34:113-119. https:// doi.org/10.1007/s10484-009-9082-5

28. Khan MS, Aouad R (2017) The effects of insomnia and sleep loss on cardiovascular disease. Sleep Med Clin 12:167-177. https:// doi.org/10.1016/j.jsmc.2017.01.005

29. Narang I, Manlhiot C, Davies-Shaw J et al (2012) Sleep disturbance and cardiovascular risk in adolescents. CMAJ 184:913-920. https://doi.org/10.1503/cmaj.111589

30. Dai H, Mei Z, An A et al (2019) Association between sleep problems and health-related quality of life in Canadian adults with chronic diseases. Sleep Med 61:26-30. https://doi.org/10.1016/j. sleep.2019.04.015

31. Deserno MK, Borsboom D, Begeer S et al (2019) Sleep determines quality of life in autistic adults: a longitudinal study. Autism Res 12:794-801. https://doi.org/10.1002/aur.2103

32. Fehm HL, Klein E, Holl R et al (1984) Evidence for extrapituitary mechanisms mediating the morning peak of plasma cortisol in man. J Clin Endocrinol Metab 58:410-414. https://doi.org/10. 1210/jcem-58-3-410

33. Anglin RE, Rosebush PI, Mazurek MF (2006) The neuropsychiatric profile of Addison's disease: revisiting a forgotten phenomenon. J Neuropsychiatry Clin Neurosci 18:450-459. https://doi. org/10.1176/jnp.2006.18.4.450

34. Thomsen AF, Kvist TK, Andersen PK et al (2006) The risk of affective disorders in patients with adrenocortical insufficiency. Psychoneuroendocrinology 31:614-622. https://doi.org/10.1016/j. psyneuen.2006.01.003

35. Ferreira L, Silva J, Garrido S et al (2017) Primary adrenal insufficiency in adult population: a Portuguese multicentre study by the Adrenal Tumours Study Group. Endocr Connect 6:935-942. https://doi.org/10.1530/EC-17-0295

36. Bahls SC, de Carvalho GA (2004) The relation between thyroid function and depression: a review. Rev Bras Psiquiatria 26:40-48. https://doi.org/10.1590/s1516-44462004000100012

37. Buning JW, Brummelman P, Koerts J et al (2016) Hydrocortisone dose influences pain, depressive symptoms and perceived health in adrenal insufficiency: a randomized controlled trial. Neuroendocrinology 103:771-778. https://doi.org/10.1159/000442985

38. Liu X, Chen W, Tu Y et al (2018) The abnormal functional connectivity between the hypothalamus and the temporal gyrus underlying depression in Alzheimer's disease patients. Front Aging Neurosci 10:1-11. https://doi.org/10.3389/fnagi.2018. 00037

39. Riemann D, Berger M, Voderholzer U (2001) Sleep and depression - results from psychobiological studies: an overview. Biol Psychol 57:67-103. https://doi.org/10.1016/S0301-0511(01) 00090-4

Publisher's Note Springer Nature remains neutral with regard to jurisdictional claims in published maps and institutional affiliations. 